DOI: $10.4274 /$ jarem.galenos.2020.3106

J Acad Res Med 2020;10(2):149-54

\title{
The Effects of HPV Test on Anxiety, Emotion and Depression in Women
}

\author{
(1) Sakine Betül Uzun1, (1) Önder Sakin2, (1) Hüseyin Çetin1, (1) Engin Ersin Şimşek1 \\ ${ }^{1}$ University of Health Sciences Turkey, Kartal Dr. Lütfi Kırdar Training and Research Hospital, Clinic of Family Medicine, İstanbul, Turkey \\ 2University of Health Sciences Turkey, Kartal Dr. Lütfi Kırdar Training and Research Hospital, Clinic of Obstetrics and Gynecology, İstanbul, Turkey
}

Cite this article as: Uzun SB, Sakin Ö, Çetin H, Şimşek EE. The Effects of HPV Test on Anxiety, Emotion and Depression in Women.

J Acad Res Med 2020;10(2):149-54

\begin{abstract}
Objective: Human papillomavirus (HPV) test is an important health screening test included in most national screening programs covering millions of women worldwide. HPV is a sexually transmitted virus, which may cause anxiety and depression in women. This study aimed at comparing the anxiety levels using a Hamilton Anxiety Rating scale and the depression levels using a Beck Depression Inventory between women who tested positive for $\mathrm{HPV}$ and those who tested negative.

Methods: Three hundred women who underwent HPV testing between 01.08.2017-01.11.2017 were randomly selected. The subjects were scored on the Beck Depression Inventory and Hamilton Anxiety Rating scale by the investigator through a face-to-face interview.

Results: No statistically significant differences were observed between $187 \mathrm{HPV}(+)$ and $113 \mathrm{HPV}(-)$ patients with respect to the depression and anxiety scores ( $p=0.183$ and $p=0.306$, respectively). While a weak negative but significant correlation was found between the time from the HPV test report date and the anxiety scores, a moderate, negative correlation was observed between the length of this time period and the depression scores. Furthermore, strong negative correlations were observed between the times elapsed from the diagnosis and the anxiety and depression scores in patients who received their results at a family health center.

Conclusion: The most serious impact of getting a positive test result for HPV occurred during relatively earlier periods and in those who received their results at a family health center. Unwanted HPV-related effects may be prevented by giving appropriate support to the right population at the very beginning.

Keywords: HPV, anxiety, depression
\end{abstract}

\section{INTRODUCTION}

Cervical cancer is one of the prominent malignancies of female genital tract. Although the importance of smear tests is surely incontestable, the importance and value of Human papillomavirus (HPV) screenings are also gradually increasing. Currently, HPV screening and vaccination programs are running in many countries (1-6).
Overall, testing positive for HPV is considered to have mental, physical, familial, or even social consequences on women. However, these consequences have been investigated by only a limited number of studies so far.

Although underestimated, several previous studies have emphasized the importance of psychosocial impact of HPV tests and the need for further studies. As mentioned earlier, cervical

ORCID IDs of the authors: S.B.U. 0000-0001-9939-7105; Ö.S. 0000-0001-6036-9975; H.Ç. 0000-0002-2844-5525; E.E.Ş. 0000-0003-3317-3461. 
cancer screenings are included in most national programs worldwide, and the significance of HPV tests for public health has been strongly emphasized (7).

A positive HPV test may cause fear, anxiety, stress, and sexual dysfunction, as well as raise accusations and questions about trust in relationships (8-11). Women who have tested positive for HPV may feel stigmatized and experience a feeling of guilt, sadness, and shame while indulging in sexual act $(7,9,11,12)$. Moreover, experiencing troubles with explanations, disclosures, and trust in relationships may eventually increase anxiety (9). Also, the association between adequate public awareness of HPV and cervical cancer have not been fully understood (13-15).

Reports from several studies have indicated that initially, a positive HPV test is more likely to bring psychological problems than an abnormal smear result $(7,11)$; this is because unlike women who have an abnormal Pap smear result, HPV (+) women are more prone to feel stigmatized and shame (16).

Finally, the approach to an HPV (+) woman should differ from that to a woman with an abnormal smear test result. In our country, an HPV test has a widespread use and is included in routine screening programs. Therefore, we believe that it is pertinent to increase the public understanding of the effects of this test on women and appropriate approaches to this issue.

In this study, we aimed at assessing the effects of testing positive for HPV on anxiety, mood, and depression in women.

\section{METHODS}

This cross-sectional and observational study included women who were directly referred to the Outpatient Clinics of Obstetrics and Gynecology of our hospital for an HPV testing and the HPV $(+)$ women referred from other health centers during the study period (1 August, 2017 to 11 November, 2017).

A total of 187 HPV (+) women, aged 20-70 years, who met the inclusion criteria were included in the study group, while $113 \mathrm{HPV}$ $(-)$ aged-matched women were included in the control group. The exclusion criteria of the study included chronic diseases, the use of medicines that might affect the mood including antidepressants, antipsychotics, and sedatives, alcohol and/ or any chemical substance addiction, and any other conditions that might lead to sexual dysfunction including vaginal stenosis, vagina dryness, active vaginitis, vaginismus, hymenal stenosis, and vagina atrophy.

Furthermore, the study data were collected by the investigator through face-to-face interviews conducted between 1 August, 2017 and 11 November, 2017. All subjects in both the study and control groups completed two psychiatric questionnaires including the Beck Depression Inventory and the Hamilton Anxiety Rating scale.

While the dependent variables in this study consisted of anxiety and depression in HPV (+) subjects, the independent variables included sociodemographic and biodemographic characteristics (such as age, educational attainment, income level, occupational status, number of children) and time from HPV test report date.

The study protocol was submitted to the Institutional Review Board and ethics approval was obtained on July 25, 2017 [Institutional Review Board (approval number: 2017/514/111/6)]. A written informed consent form was obtained from all patients prior to the study.

\section{Statistical Analysis}

Data were analyzed using the SPSS software version 17.0. The normality of the variables was assessed using histogram graphics and the Kolmogorov-Smirnov test. The descriptive statistics included means, standard deviation, minimum, and maximum. Moreover, the $2 \times 2$ contingency Pearson's chi-square and Fisher's exact tests were used for the comparisons. Additionally, while the Mann-Whitney $U$ test was used for the comparisons of nonnormally distributed (non-parametric) data between two groups, the Kruskal-Wallis test was used to compare more than two groups. Besides, the Spearman's Correlation test was used for intergroup comparisons of numerical data. A p-value $<0.05$ was considered as statistically significant.

\section{RESULTS}

Of the 300 studied subjects, $35.67 \%$ were elementary school graduates, $77 \%$ were married, $49 \%$ were unemployed, and $48.33 \%$ had a monthly income ranging from 1,500 to $4,500 \mathrm{TL}$. The mean age of the participants was $42.19 \pm 9.29$ years and the mean number of children per subject was $1.98 \pm 1.27$.

Interestingly, the analysis of the demographic characteristics by HPV results did not reveal any statistically significant associations between HPV results and age, educational attainment, marital status, number of children, income level, Beck Depression Inventory, and Hamilton Anxiety Rating scale scores ( $p>0.05$ ).

In addition, no statistically significant associations were observed between the analysis of Beck Depression Inventory and Hamilton Anxiety Rating scale scores by HPV results ( $p>0.05)$.

Moreover, the analysis of the distribution of demographic characteristics by HPV results indicated that the rates of HPV (+) subjects were higher among employees (58.33\%), unemployed women $(53.74 \%)$, and pensioners $(60 \%)$ than in students $(0 \%)$ (p:0.009) (Table 1).

The analysis of the mean age, number of children, and Beck Depression Inventory and Hamilton Anxiety Rating scale scores by the HPV results revealed that Beck Depression Inventory scores were lower in HPV (-) subjects $(11.93 \pm 8.86)$ compared to the HPV $(+)$ subjects $(14.13 \pm 9.08)(p=0.029)$ (Table 2$)$.

Further, the analysis of age, educational attainment, number of children, income level, Beck Depression Inventory and Hamilton Anxiety Rating scale scores by the time from HPV testing revealed a very weak significant negative correlation $(r=-0.167)$ between the time from HPV testing and Hamilton Anxiety Rating scale 
scores $(p=0.004)$. However, no significant correlation was found between the duration of HPV infection and the mean age, educational attainment, number of children, income level, and Beck Depression Inventory scores ( $p>0.05$ ).

The analysis of Beck Depression Inventory and Hamilton Anxiety Rating scale scores by the time from HPV testing in HPV (+) patients revealed significant correlations between the time from HPV testing and the Beck Depression Inventory and Hamilton Anxiety Rating scale scores: a statistically significant moderate negative correlation was found between the time from HPV test report date and the Beck Depression Inventory scores in HPV $(+)$ patients $(r=-0.404)(p<0.01)$, as well as between the time from HPV test report date and the Hamilton Anxiety Rating scale scores in HPV $(+)$ patients ( $r=$ $-0.436)(p<0.01)$.

\section{Table 1. Demographic characteristics of patients according to the human papillomavirus results}

\begin{tabular}{|c|c|c|c|c|c|c|c|c|}
\hline & \multicolumn{6}{|c|}{ HPV result } & \multirow{3}{*}{$p$} \\
\hline & & \multicolumn{2}{|c|}{ Positive } & \multicolumn{2}{|c|}{ Negative } & \multicolumn{2}{|c|}{$\begin{array}{l}\text { Positive at family } \\
\text { health center }\end{array}$} & \\
\hline & & $\mathrm{n}$ & $\%$ & $\mathrm{n}$ & $\%$ & $\mathrm{n}$ & $\%$ & \\
\hline \multirow{2}{*}{ Age } & $<40$ & 73 & $(58.40)$ & 40 & (32.00) & 12 & $(9.60)$ & \multirow{2}{*}{0.05} \\
\hline & $>40$ & 95 & (54.29) & 73 & $(41.71)$ & 7 & $(4.00)$ & \\
\hline \multirow{5}{*}{ Education } & Illiterate & 5 & (83.33) & 1 & $(16.67)$ & 0 & $(0.00)$ & \multirow{5}{*}{$0.82 C$} \\
\hline & Primary school & 58 & $(54.21)$ & 39 & (36.45) & 10 & (9.35) & \\
\hline & Middle school & 31 & $(55.36)$ & 22 & (39.29) & 3 & (5.36) & \\
\hline & High school & 41 & $(56.94)$ & 28 & $(38.89)$ & 3 & $(4.17)$ & \\
\hline & University and above & 33 & $(55.93)$ & 23 & (38.98) & 3 & $(5.08)$ & \\
\hline \multirow{3}{*}{ Marital status } & Married & 122 & (52.81) & 95 & (41.13) & 14 & (6.06) & \multirow{3}{*}{0.26} \\
\hline & Single & 11 & $(64.71)$ & 5 & $(29.41)$ & 1 & (5.88) & \\
\hline & Widow & 35 & $(67.31)$ & 13 & $(25.00)$ & 4 & (7.69) & \\
\hline \multirow{4}{*}{ Job } & Working & 77 & (58.33) & 48 & (36.36) & 7 & (5.30) & \multirow{4}{*}{0.00} \\
\hline & Not working & 79 & (53.74) & 57 & (38.78) & 11 & (7.48) & \\
\hline & Retired & 12 & $(60.00)$ & 8 & $(40.00)$ & 0 & $(0.00)$ & \\
\hline & Student & 0 & $(0.00)$ & 0 & $(0.00)$ & 1 & $(100.00)$ & \\
\hline \multirow[t]{2}{*}{ Number of children } & 2 and less & 119 & $(57.77)$ & 77 & (37.38) & 10 & $(4.85)$ & \multirow{2}{*}{0.266} \\
\hline & 3 and more & 49 & $(52.13)$ & 36 & (38.30) & 9 & (9.57) & \\
\hline \multirow{4}{*}{ Beck1 } & Normal & 62 & $(52.10)$ & 49 & (41.18) & 8 & (6.72) & \multirow{4}{*}{0.24} \\
\hline & Mild & 56 & $(53.85)$ & 43 & $(41.35)$ & 5 & $(4.81)$ & \\
\hline & Moderate & 36 & (63.16) & 15 & (26.32) & 6 & (10.53) & \\
\hline & Severe & 14 & $(70.00)$ & 6 & $(30.00)$ & 0 & $(0.00)$ & \\
\hline \multirow{2}{*}{ Beck2 } & No depression & 62 & $(52.10)$ & 49 & (41.18) & 8 & (6.72) & \multirow{2}{*}{0.541} \\
\hline & There is depression & 106 & $(58.56)$ & 64 & (35.36) & 11 & (6.08) & \\
\hline \multirow{3}{*}{ Hamilton1 } & None & 29 & $(48.33)$ & 27 & $(45.00)$ & 4 & (6.67) & \multirow{3}{*}{0.325} \\
\hline & Minor & 84 & (57.93) & 49 & (33.79) & 12 & (8.28) & \\
\hline & Major & 55 & $(57.89)$ & 37 & (38.95) & 3 & (3.16) & \\
\hline \multirow{2}{*}{ Hamilton2 } & No anxiety & 29 & (48.33) & 27 & $(45.00)$ & 4 & (6.67) & \multirow{2}{*}{0.392} \\
\hline & There is anxiety & 139 & $(57.92)$ & 86 & (35.83) & 15 & (6.25) & \\
\hline
\end{tabular}


Table 2. Average of age, number of children, Beck and Hamilton values according to the human papillomavirus result

\begin{tabular}{|c|c|c|c|c|c|}
\hline & \multicolumn{4}{|c|}{ HPV result } & \multirow[t]{3}{*}{$p$} \\
\hline & \multicolumn{2}{|l|}{ Negative } & \multicolumn{2}{|l|}{ Positive } & \\
\hline & Average & $\pm \mathrm{SD}$ & Average & $\pm \mathrm{SD}$ & \\
\hline Age & 42.41 & \pm 9.39 & 42.06 & \pm 9.25 & 0.469 \\
\hline Number of children & 2.02 & \pm 1.21 & 1.96 & \pm 1.30 & 0.596 \\
\hline
\end{tabular}

The correlation analysis of the Beck Depression Inventory and Hamilton Anxiety Rating scale scores by the time from HPV testing in HPV (+) subjects who underwent an HPV testing at the Family Health Center ( $\mathrm{FHC}$ ) revealed a significant correlation between the time from HPV test report date and the Beck Depression Inventory and Hamilton Anxiety Rating scale scores. However, in patients who underwent HPV testing at the FHC, a strong negative correlation was found between the time from HPV test report date and the Beck Depression Inventory $(r=-0.611)(p<0.01)$, as well as between the time from HPV test report date and the Hamilton Anxiety Rating scale scores ( $r=$ $-0.436)(p<0.01)$.

\section{DISCUSSION}

In the present study, the states of depression and anxiety was assessed in a total of 300 subjects, including 187 HPV (+) women and 113 HPV (-) women. Moreover, no statistically significant differences were found between the HPV $(+)$ and $(-)$ women with respect to their depression and anxiety scores $(p=0.183, p=0.306$, respectively). Although the difference did not reach the level of significance, the higher numerical values detected in all HPV (+) groups in comparison to the HPV (-) groups were remarkable. While $73 \%$ of the subjects who scored in the moderate range and $70 \%$ who scored in the severe range on the Beck Depression Inventory were in the HPV (+) group, $66 \%$ of the subjects who scored in the minor anxiety range and $61 \%$ who scored in the major anxiety range on the Hamilton Anxiety Rating scale were in the HPV (+) group.

Moreover, the analysis of the depression scores by the age and number of children revealed significantly lower scores in the HPV $(-)$ group in comparison to the HPV $(+)$ group $(p=0.029)$.

The time interval between the HPV test report date and the assessment date has been considered important in this patient group, as these patients may experience an acute anxiety and stress when they get test results. The fear of cancer may cause a tendency to undergo interventional procedures, colposcopic examinations, and biopsies in these patients, and they may even force their physician to perform these procedures. As a result, even the unnecessary interventions, and tissue sampling procedures may be performed.
A literature search revealed evidence from several studies indicating that the level of stress might be significantly increased initially after getting a positive HPV test result. Quantitative studies support that a positive HPV test is more likely to bring psychological load than an abnormal smear result and that this effect may lessen over time (17). In our study, the subjects were assessed at five different time intervals; "the first two weeks," "week 2 to week 4," "month 1 to month 3," "month 6 to month $12, "$ and "after month 12." The assessment of anxiety and depression scores pointed out a negative, week but significant correlation between anxiety scores and the time from the HPV test report date. In other words, initial anxiety scores were significantly higher after getting a positive HPV test result. The assessment of depression scores by the same time intervals revealed a negative, moderate, significant correlation between the time from the positive HPV test report date and depression scores. In other words, initial depression scores were significantly higher after getting a positive HPV test result.

Furthermore, HPV positivity is typically associated with increased anxiety and depression scores, and intense fear and anxiety especially in the early period. This increasing fear and anxiety decreases with the help of researches, medical examinations, interviews, and explanations.

Another point to consider in this patient group is the site where the diagnosis was made. In our country, cervical HPV screening programs are performed by FHCs. All women over the age of 30 years are covered by routine screening programs and may undergo HPV testing. Test results are revealed to patients for the first time at FHCs. While women who test negative for HPV are not referred to other centers, those who test positive are referred to gynecologic oncology outpatient clinics at tertiary healthcare facilities. After getting a positive test result, patients are advised to contact a reference center. Negative interactions may be minimized if during this process, patients receive correct, and adequate information from a specialist in this field.

In this study, a strong negative correlation was also found between the test report date and anxiety and depression scores in subjects who were tested for HPV at an FHC. This finding might have resulted from inadequate information provided to the patients at FHCs as well as the inclusion of the 
Informed Consent: A written informed consent form was obtained from all patients prior to the study.

Peer-review: Externally peer-reviewed.

Author Contributions: Concept - Ö.S., S.B.U., E.E.Ş.; Design - Ö.S., S.B.U., E.E.S.; Supervision - E.E.S.; Data Collection and/or Processing Ö.S., S.B.U.; Analysis and/or Interpretation - S.B.U., H.Ç.; Literature Search - Ö.S., S.B.U.; Writing Manuscript - Ö.S., S.B.U., E.E.Ş., H.Ç.; Critical Review - Ö.S., S.B.U., E.E.Ş., H.Ç.

Conflict of Interest: The authors have no conflict of interest to declare.

Financial Disclosure: The authors declared that this study has received no financial support.

\section{REFERENCES}

1. Smith MA, Edwards S, Canfell K. Impact of the National Cervical Screening Programme in New Zealand by age: analysis of cervical cancer trends 1985-2013 in all women and in Māori women. Cancer Causes Control 2017; 28: 1393-404.

2. Awua AK, Wiredu EK, Afari EA, Tijani AS, Djanmah G, Adanu RMK. A tailored within-community specimen collection strategy increased uptake of cervical cancer screening in a cross-sectional study in Ghana. BMC Public Health 2017; 18: 80.

3. Cuzick J, Myers O, Lee JH, Shi Y, Gage JC, Hunt WC, et al. Outcomes in women with cytology showing atypical squamous cells of undetermined significance with vs without human papillomavirus testing. JAMA Oncol 2017; 3: 1327-34

4. Schiffman M, Kinney WK, Cheung LC, Gage JC, Fetterman B, Poitras $\mathrm{NE}$, et al. Relative Performance of HPV and Cytology Components of Cotesting in Cervical Screening. J Natl Cancer Inst 2018; 110: 501-8.

5. Silver MI, Rositch AF, Phelan-Emrick DF, Gravitt PE. Uptake of HPV testing and extended cervical cancer screening intervals following cytology alone and Pap/HPV cotesting in women aged 30-65 years. Cancer Causes Control. Cancer Causes Control 2018; 29: 43-50.

6. Senkomago V, Royalty J, Miller JW, Buenconsejo-Lum LE, Benard VB, Saraiya M. Cervical cancer screening in the National Breast and Cervical Cancer Early Detection Program (NBCCEDP) in four US-Affiliated Pacific Islands between 2007 and 2015. Cancer Epidemiol 2017; 50: 2607.

7. McCaffery K, Waller JO, Forrest S, Cadman L, Szarewski A, Wardle J. Testing positive for human papillomavirus in routine cervical screening: examination of psychosocial impact. BJOG 2004; 111: 1437-43.

8. Maggino T, Casadei D, Panontin E, Fadda E, Zampieri MC, Donà MA, et al. Impact of an HPV diagnosis on the quality of life in young women. Gynecol Oncol 2007; 107(1 Suppl 1): 175-9.

9. McCaffery K, Waller J, Nazroo J, Wardle J. Social and psychological impact of HPV testing in cervical screening: a qualitative study. Sex Transm Infect 2006; 82: 169-74.

10. Ramirez JE, Ramos DM, Clayton L, Kanowitz S, Moscicki AB. Genital human papillomavirus infections: Knowledge, perception of risk, and actual risk in a nonclinic population of young women. J Womens Health 1997; 6: 113-21.

11. Maissi E, Marteau TM, Hankins M, Moss S, Legood R, Gray A. Psychological impact of human papillomavirus testing in women with borderline or mildly dyskaryotic cervical smear test results: cross sectional questionnaire study. BMJ 2004; 328: 1293.

12. Kahn JA, Slap GB, Bernstein DI, Tissot AM, Kollar LM, Hillard PA, et al. Personal meaning of human papillomavirus and Pap test results in adolescent and young adult women. Health Psychol 2007; 26: 192200.

13. Anhang R, Wright TC Jr, Smock L, Goldie SJ. Women's desired information about human papillomavirus. Cancer 2004; 100: 315-20.

14. Waller JO, McCaffery K, Wardle J. Beliefs about the risk factors for cervical cancer in a British population sample. Prev Med 2004; 38: 74553.

15. Yacobi E, Tennant C, Ferrante J, Pal N, Roetzheim R. University students' knowledge and awareness of HPV. Prev Med 1999; 28: 535-41.

16. Waller JA, Marlow LAV, Wardle J. Anticipated shame and worry following an abnormal Pap test result: the impact of information about HPV. Prev Med 2009; 48: 415-9.
Ethics Committee Approval: The study protocol was submitted to the 2017 (institutional review board approval number: 2017/514/111/6). 
17. Maissi E, Marteau TM, Hankins M, Moss S, Legood R, Gray A. The psychological impact of human papillomavirus testing in women with borderline or mildly dyskaryotic cervical smear test results: 6-month follow-up. Br J Cancer 2005; 92: 990-4.
18. Waller J, Marlow LAV, Wardle J. The association between knowledge of HPV and feelings of stigma, shame and anxiety. Sex Transm Infect 2007; 83: 155-9. 